\title{
Aswaja NU Center dan Perannya sebagai Benteng Aqidah
}

\section{Munawir}

Institut Agama Islam Darussalam, Banyuwangi

\begin{abstract}
One of the phenomena experienced recently by the Islamic community is the incomprehension in the aqidah and other conviction problems, and the community incomprehension on the Islamic methods and practices. This phenomenon draws the researcher's attention to conduct study on the role of ASWAJA NU CENTER Banyuwangi in fortifying Aqidah Ahlus Sunnah Wal Jama'ah. The result showed that ASWAJA NU CENTER could give the best service to the Muslim society in facilitating the comprehension of truthful aqidah correspond to the lesson of the Prophet SAW which is called Ahlus Sunnah Wal Jama'ah by giving motivation in constructing a more qualified and noble education, giving speeches in mushollas and mosques, and conducting trainings on Aswaja.
\end{abstract}

Keywords: Aswaja NU Center, Aqidah, Ahlus Sunnah Wal Jama'ah

\begin{abstract}
Abstrak
Salah satu fenomena yang dialami umat Islam sekarang ini adalah ketidakpahaman dalam masalah aqidah dan masalah-masalah keyakinan lainnya, serta ketidakpahaman umat akan metodologi dan pengamalan Islam. Sehingga peneliti tertarik untuk melakukan penelitian tentang Peran ASWAJA NU CENTER Banyuwangi dalam Membentengi Aqidah Ahlus Sunnah Wal Jama'ah. Hasil penelitian adalah ASWAJA NU CENTER mampu memberikan pelayanan yang terbaik kepada masyarakat muslim dalam membantu tentang pemahaman aqidah yang benar sesuai ajaran Rasulullah SAW yang disebut Ahlus Sunnah Wal Jama'ah dengan cara memberikan motivasi dalam membangun pendidikan yang lebih berkualitas dan berakhlaq, memberikan ceramah di mushola dan masjid, mengadakan pelatihan tentang Aswaja
\end{abstract}

Kata Kunci: Aswaja, NU Center,Aqidah 


\section{Pendahuluan}

Aswaja kepanjangan dari "Ahlus Sunnah Wal Jama’ah". Artinya orang-orang yang menganut atau mengikuti sunnah Nabi Muhammad SAW, dan Wal Jama'ah berarti mayoritas umat atau mayoritas sahabat Nabi Muhammad SAW. Jadi definisi Ahlus Sunnah Wal Jama’ah yaitu: "Orang-orang yang mengikuti sunnah Nabi Muhammad SAW dan mayoritas sahabat (maa ana alaihi wa ashabii), baik di dalam syariat (hukum Islam) maupun aqidah dan tasawuf."

Untuk menegakkan prinsip-prinsip ajaran ahlu sunnah wal jama'ah dan prinsip dasar organisasi, maka KH. Hasyim Asy’ari merumuskan kitab Qanun Asasi (prinsip dasar), dan juga merumuskan kitab I’tiqad Ahlus Sunnah Wal Jama'ah. Kedua kitab tersebut, kemudian diejawantahkan dalam Khittah NU, yang dijadikan dasar dan rujukan sebagai warga NU dalam berpikir dan bertindak dalam bidang sosial, keagamaan, dan politik.

Khusus untuk membentengi keyakinan warga NU agar tidak terkontaminasi oleh paham-paham sesat yang dikampanyekan oleh kalangan modernis, KH. Hasyim Asy'ari menulis kitab risalah Ahlus Sunnah Wal Jama’ah yang secara khusus menjelaskan soal bid'ah dan sunah. Sikap lentur NU sebagai titik pertemuan pemahaman aqidah, fikih, dan tasawuf versi Ahlus Sunnah Wal Jama'ah telah berhasil memproduksi pemikiran keagamaan yang fleksibel, mapan, dan mudah diamalkan pengikutnya.

Dalam perkembangannya kemudian para ulama' NU di Indonesia menganggap bahwa Aswaja yang diajarkan oleh $\mathrm{KH}$ Hasyim Asy'ari sebagai upaya membumikan atau menginstitusikan prinsip-prinsip tawasuth (moderat), tasamuh (toleran) dan tawazzun (seimbang) serta taaddul (keadilan). Prinsip-prinsip tersebut merupakan landasan dasar dalam mengimplimentasikan Aswaja.

Seiring dengan derasnya perkembangan ilmu pengetahuan dalam berbagai bidang menuntut kita agar terus memacu diri mengkaji Ahlus Sunnah Wal Jama’ah dari berbagai aspeknya, agar warga nahdliyin dapat memahami dan memperdalam, menghayati dan mengejawantahkan warisan ulama al salaf al salih yang berserakan dalam tumpukan kutub al turast, maka PWNU Jawa Timur terinspirasi membentuk lembaga yang diberi nama ASWAJA NU CENTER. Keberadaaan Aswaja NU Center ini tidak hannya ditingkat wilayah/propinsi akan tetapi juga di tingkat Kabupaten hususnya Aswaja NU Center Kab. Banyuwangi. Lembaga ini memiliki visi untuk membentuk masyarakat NU yang mampu membentengi diri dari faham-faham lain serta dapat meyakinkan orang lain atas kebenaran faham ASWAJA NU dan memiliki misi mengaktualisasi pemahaman umat tentang keislaman ASWAJA NU, meningkatkan pemahaman, penghayatan, pengalaman (menginternalisasi) Islam. Secara tidak langsung ASWAJA NU center Kab. Banyuwangi mampu membentengi aqidah warga nahdliyin dalam bermasyarakat dengan orang yang mempunyai paham yang 
berbeda. Lembaga ini sudah membuktikan keberhasilannya berdakwah di tingkat nasional maupun internasional. Seperti yang telah dilakukan di Batam dan Malaysia. Seminar nasional "Menyikapi konflik Sunni-Syiah dalam bingkai NKRI" Seminar tentang Ahlus Sunnah Wal Jama'ah dan debat terbuka dengan orang wahabi. Ini membuktikan bahwa ASWAJA NU CENTER mampu memperkokoh aqidah umat islam hususnya warga nahdiyyin.

Seperti halnya yang ada di Dusun jalen desa Setail Kec. Genteng Kab. Banyuwangi sudah terdapat beberapa media yang mempunyai target memudarkan aqidah Ahlus Sunnah Wal Jama’ah yang ada di masyarakat. Bahkan sudah ada beberapa keluarga yang mengikuti faham faham tersebut. Untuk itu sebelum aqidah masyarakat semakin diobok-obok. Maka ASWAJA NU CENTER Banyuwangi anak cabang dari ASWAJA NU Jawa Timur harus meningkatakan usaha dalam rangka membentengi dengan kokoh aqidah Ahlus Sunnah Wal Jama’ah khususnya masyarakat Dusun Jalen Desa Setail Kec. Genteng Kab. Banyuwangi.

Dari paparan di atas, maka peneliti tertarik untuk meneliti lebih lanjut bagaimana Peran ASWAJA NU CENTER Banyuwangi dalam Membentengi Aqidah Ahlus sunnah Wal Jama’ah Dusun Jalen Desa Setail Kec. Genteng Kab. Banyuwangi Tahun 2015”

Istilah Aswaja dalam masyarakat indonesia adalah Ahlus sunnah wal-jama'ah. Ahlus Sunnah Wal-jama’ah terdiri dari tiga kata yakni: 1). Ahl, berarti keluarga, golongan atau pengikut, 2). Al-sunnah, berarti segala sesuatu yang telah diajarkan oleh rosulullah baik berupa perkataan, perbuatan dan ketetapan, 3). Al- Jama’ah berarti apa yang telah disepakati oleh para shohabat Rosulullah SAW.

Menurut KH.M.Hasyim Asy'ari, Ahlus Sunnah Wl-jama'ah adalah kelompok ahli tafsir, ahli hadist dan ahli fiqih, yang selalu mengikuti dan berpegang teguh dengan sunnah Nabi dan Sunnah Khulafa'urrosyidin, Muhyidin Abdusshomad $(2008,6)$

Dari definisi ini dapat dipahami bahwa Ah-lussunnah wa-jama'ah bukanlah aliran baru yang muncul sebagai reaksi dari beberapa aliran yang menyimpang dari ajaran islam yang hakiki, tetapi Ahlussunnah Wal-Jama'ah adalah islam yang murni sebagaimana yang diajarkan oleh Rosulullah dan para shohabatnya. Oleh karena itu ada seorangpun yang menjadi pendiri ajaran Ahlussunnah Wal-jama’ah yang ada hanyalah ulama' yang telah merumuskan kembali ajaran islam tersebut setelah lahirnya beberapa faham dan aliran keagamaan yang berusaha mengkaburkan ajaran rosulullah dan para shohabatnya. Tim Aswaja NU Center PWNU, (2015,7 )

Paham ahlussunnah Wal-jama’ah mecakup aspek aqidah, syari’ah dan akhlak/tasyawuf. Dalam bidang aqidah/tauhid mengikuti pemikiran Abu Hasan Al-Asy'ari dan al-maturidi. Dalam Masalah Syari'ah/Fiqih mengikuti mdzhab empat yakni imam syafi'i. iamam Hanafi, imam maliki dan imam Hanbali. Dalam bidang tasyawuf mengikuti pendapat imam AlGhozali dan imam Al-junaidi. 
Adapun ciri-ciri ajaran Ahlussunnah Wal-jama'ah yang diajarkan oleh Rosulullah dan para shohabat adalah:

1. At-Tawassuth atau sikap tengah-tengah, sedang-sedang, tidak ekstrim kiri ataupun ekstrim kanan. firman Allah SWT:

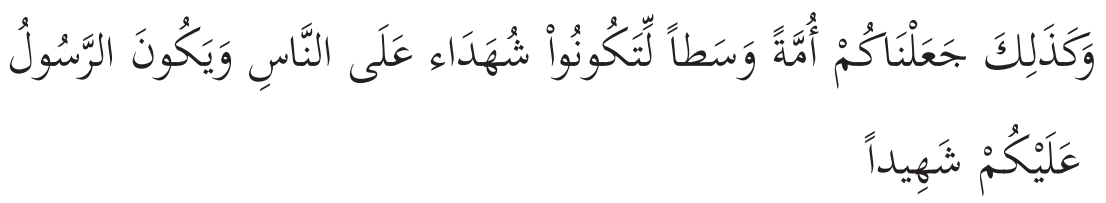

Artinya : Dan demikianlah kami jadikan kamu sekalian (umat Islam) umat pertengahan (adil dan pilihan) agar kamu menjadi saksi (ukuran penilaian) atas (sikap dan perbuatan) manusia umumnya dan supaya Allah SWT menjadi saksi (ukuran penilaian) atas (sikap dan perbuatan) kamu sekalian. (QS al-Baqarah: 143).

2. At-Tawazun atau seimbang dalam segala hal, terrnasuk dalam penggunaan dalil 'aqli (dalil yang bersumber dari akal pikiran rasional) dan dalil naqli (bersumber dari AlQur’an dan Hadits). Firman Allah SWT:

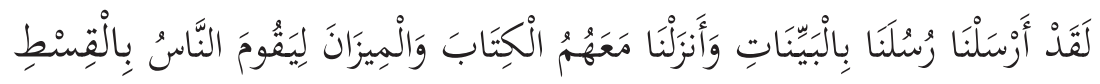

Artinya : Sunguh kami telah mengutus rasul-rasul kami dengan membawa bukti kebenaran yang nyata dan telah kami turunkan bersama mereka Al-Kitab dan neraca (penimbang keadilan) supaya manusia dapat melaksanakan keadilan. (QS al-Hadid: 25).

3. Al-I'tidal atau tegak lurus. Dalam Al-Qur'an Allah SWT berfirman:

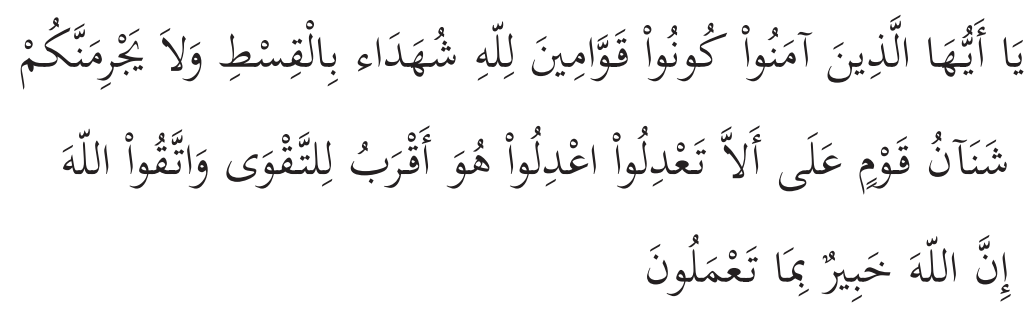

Artinya : Wahai orang-orang yang beriman hendaklah kamu sekalian menjadi orang-orang yang tegak membela (kebenaran) karena Allah menjadi saksi (pengukur kebenaran) yang adil. Dan janganlah kebencian kamu pada suatu kaum menjadikan kamu berlaku tidak adil. Berbuat adillah karena keadilan itu lebih mendekatkan pada taqwa. Dan bertaqwalah kepada Allah, karena sesungguhnya Allah Maha Melihat apa yang kamu kerjakan. (QS al-Maidah: 8) 
4. At-Tasamuh atau toleransi. Yakni menghargai perbedaan serta menghormati orang yang memiliki prinsip hidup yang tidak sama. Namun bukan berarti mengakui atau membenarkan keyakinan yang berbeda tersebut dalam meneguhkan apa yang diyakini. Firman Allah SWT:

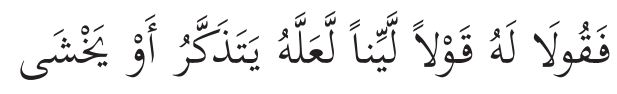

Artinya : Maka berbicaralah kamu berdua (Nabi Musa AS dan Nabi Harun AS) kepadanya (Fir'aun) dengan kata-kata yang lemah lembut dan mudahmudahan ia ingat dan takut. (QS. Thaha: 44)

Ayat ini berbicara tentang perintah Allah SWT kepada Nabi Musa AS dan Nabi Harun AS agar berkata dan bersikap baik kepada Fir’aun. Al-Hafizh Ibnu Katsir (701-774 H/13021373 M) ketika menjabarkan ayat ini mengatakan, "Sesungguhnya dakwah Nabi Musa AS dan Nabi Harun AS kepada Fir'aun adalah menggunakan perkataan yang penuh belas kasih, lembut, mudah, dan ramah. Hal itu dilakukan supaya lebih menyentuh hati, lebih dapat diterima dan lebih berfaedah". (Tafsir al-Qur'anil 'Azhim, juz III hal 206).

ASWAJA NU CENTER merupakan sebuah perangkat pelaksana program guna untuk membentengi masyarakat yang beraqidah ahlus Ahlus Sunnah Wal Jama’ah ala NU dari faham-faham Islam garis keras atau radikal baik melalui dakwah secara langsung atau melalui media cetak dan elektronik.

ASWAJA NU CENTER, kemunculannya diawali dari kajian Islam yang memfokuskan materi bahasannya pada bidang keaswajaan. Kajian tersebut dikenal dengan kajian Islam Ahlus Sunnah Wal Jama'ah atau disingkat Kiswah. kajian Islam Ahlus Sunnah Wal Jama’ah (Kiswah) ini diprakarsai oleh para pembesar NU di PWNU Jawa Timur, mulai dari Rais Syuriah hingga katib Syuriah dan telah dibahas pada saat rapat harian di PWNU Jawa Timur. Sehingga sesuai amanat Konperwil pada tanggal 31 Januari 2011 bertepatan dengan peringatan Harlah NU ke-85 di PWNU Jawa Timur dilaksanakan launching perangkat pelaksana program yang berisikan tentang kajian Islam keaswajaan yang diberi nama ASWAJA NU CENTER Jawa Timur oleh wakil ketua umum Pengurus Besar Nahdhatul Ulama : Drs H. As'ad Said Ali.

Aswaja NU Center mempunyai lima divisi, yakni divisi Kiswah (Kajian Islam ala Ahlus Sunnah Wal Jama’ah), Dakwah (Dauroh dan kaderisasi Ahlus Sunnah Wal Jama’ah), Makwah (maktabah Ahlus Sunnah Wal Jama’ah), Uswah (usaha sosialisasi Ahlus Sunnah Wal Jama’ah), dan Biswah (Bimbingan dan Solusi Ahlus Sunnah Wal Jama’ah).

Adapun Tujuan, Visi, Dan Misi Aswaja Center Sebagai Berikut :

a. Tujuan : Membentuk masyarakat NU yang mampu membentengi diri dari faham- 
faham lain serta dapat meyakinkan orang lain atas kebenaran faham ASWAJA NU.

b. Visi : Terwujudnya wawasan keislaman yang bermanhaj Ahlus Sunnah Wal Jama’ah ala NU, sesuai dengan keberagamaan Rasulullah SAW bersama para sahabat.

c. Misi :

1) Mengaktualisasikan pemahaman ummat tentang keislaman ASWAJA NU

2) Meningkatkan pemahaman, penghayatan, pengamalan nilai Islam pada manhaj ASWAJA NU sebagai perilaku umat dalam kehidupan sehari-hari.

2. Aqidah Ahlus Sunnah Wal Jama’ah

a. Pengertian Aqidah/Akhlak

Di bidang aqidah atau tauhid dalam memurnikan imam umat muslim agar sesuai dengan ajaran Rosul dan para sahabat, kita harus mengikuti rumusan dari 2 Ulama Salaf :

1) Al-Asy'ari (Abu Hasan Ali Bin Isma’il Al-Asy’ari) lahir di Basrah $260 \mathrm{H} / 874 \mathrm{M}$ Wafat 324 H/ 936 M, Beliau masih dzuriah sahabat Rosul, Abu Musa Al-Asy’ari

2) Al-Maturidi (Abu Mansur Muhammad Bin Muhammad Bin Mahmud Al-Maturidi) Lahir di Maturid dan wafat di Samarkand 333H/ 944 M.

Di bidang fiqih dalam memurnikan syariat Islam umat muslim agar sesuai ajaran Rosulullah dan para sahabat, kita harus mengikuti rumusan dari 4 ulama salaf :

1) Al-Hanafi : (Abu Hanifah Annu'man Bin Tsabit Bin Zauti) lahir di Kuffah $80 \mathrm{H}$ Wafat $150 \mathrm{H}$.

2) Al-Maliki : (Malik Bin Anas Bin Amar Al-Asbahi Al-Yamani) lahir di Madinah 93 $\mathrm{H}$ - Wafat $179 \mathrm{H}$.

3) As-Syafi'i : (Muhammad Bin Idris Bin Abbas Bin Ustman Bin Syafi'i Bin Sa'ib Bin Abu Yazid Bin Hasyim Bin Abd Mutolib Abd Manaf) lahir di Ghuzzah Palestina Jum’at akhir bulan Rojab $150 \mathrm{H}$ - Wafat $204 \mathrm{H}$.

4) Al-Hambali : (Ahmad Bin Muhammad Bin Hambal Bin Hilal Bin Asad Bin Idris Bin Abdullah Bin Hasan Assyaibani Al-Marwadzi Al-Baghdadi ) lahir di Baghdad Rabi'ul Awal $164 \mathrm{H}$ - Wafat $241 \mathrm{H}$.

Di bidang akhlaq dalam rangka memurnikan ajaran tasawuf agar sesuai dengan ajaran Rosul dan para sahabat kita harus mengikuti rumusan 2 ulama salaf :

1) Imam Al-Junaidi Al-Baghdadi Wafat 297 H/ 910 M.

2) Imam Al-Ghozali : Abu Hamid Muhammad Bin Muhammad Bin Muhammad AlGhozali. Lahir di Thus tahun $450 \mathrm{H}$. 
Kenapa demikian, alasannya adalah sebagai berikut :

1) Karena dari keenam ulama' tersebutlah yang diakui oleh mayoritas ulama' Islam dunia memiliki keilmuan yang sangat mumpuni dan telah mampu merumuskan ajaran Nabi dan jalan para sahabatnya sehingga bagi orang secara umum dapat tercapailah tujuan mengikuti seluruh ajaran Nabi dan para sahabatnya secara menyeluruh tanpa ada ketimpangan.

2) Enam ulama' tersebut memiliki kitab induk yang termodifikasi dan memiliki murid atau kader secara terus menerus atau bersambung tanpa terputus yang mampu mengembangkan ilmunya ke seluruh penjuru dunia sampai hari ini, sehingga rumusan mereka tidak pernah rapuh dan musnah ditelan masa.

3) Bagi orang secara umum tidaklah mampu bila harus mengembalikan seluruh hukum masalah agama langsung kepada Al-Qur'an, Hadist dan jalan para sahabatnya yang jumlahnya mencapai ratusan ribu dalil, sehingga dicukupkanlah bagi orang jaman sekarang untuk mengikuti apa yang sudah mereka rumuskan. Dengan artian bagi orang yang menyelisihi rumusan mereka dapat dikatakan keluar dari sebuah jalan kebenaran Islam.

Dalam tataran praktis, sebagaimana dijelaskan KH. Ahmad Shiddiq bahwa prinsip prinsip ini dapat terwujudkan dalam beberapa hal sebagai berikut: (Khitthah Nahdliyah, 40-44)

1) Aqidah

a) Keseimbangan dalam penggunaan dalil 'aqli dan dalil naqli.

b) Memurnikan aqidah dari pengaruh luar Islam.

c) Tidak gampang menilai salah atau menjatuhkan vonis syirik, bid'ah, apalagi kafir.

2) Syari'ah

a) Berpegang teguh pada Al-Qur'an dan Hadits dengan menggunanakan metode yang dapat dipertanggungjawabkan secara ilmiah.

b) Akal baru dapat digunakan pada masalah yang yang tidak ada nash yang jelas (sharih/qotht'i).

c) Dapat menerima perbedaan pendapat dalam menilai masalah yang memiliki dalil yang multi-interpretatif (zhanni).

3) Tashawwuf/ Akhlaq

a) Tidak mencegah, bahkan menganjurkan usaha memperdalam penghayatan ajaran Islam, selama menggunakan cara-cara yang tidak bertentangan dengan prinsipprinsip hukum Islam.

b) Mencegah sikap berlebihan (ghuluw) dalam menilai sesuatu.

c) Berpedoman kepada akhlak yang luhur. Misalnya sikap syaja'ah atau berani (antara 
penakut dan ngawur atau sembrono), sikap tawadhu' (antara sombong dan rendah diri) dan sikap dermawan (antara kikir dan boros).

4) Pergaulan antar golongan

a) Mengakui watak manusia yang senang berkumpul dan berkelompok berdasarkan unsur pengikatnya masing-masing.

b) Mengembangkan toleransi kepada kelompok yang berbeda.

c) Pergaulan antar golongan harus atas dasar saling menghormati dan menghargai.

d) Bersikap tegas kepada pihak yang nyata-nyata memusuhi agama Islam.

5) Kehidupan bernegara

a) NKRI (Negara Kesatuan Republik Indanesia) harus tetap dipertahankan karena merupakan kesepakatan seluruh komponen bangsa.

b) Selalu taat dan patuh kepada pemerintah dengan semua aturan yang dibuat, selama tidak bertentangan dengan ajaran agama.

c) Tidak melakukan pemberontakan atau kudeta kepada pemerintah yang sah.

d) Kalau terjadi penyimpangan dalam pemerintahan, maka mengingatkannya dengan cara yang baik.

6) Kebudayaan

a) Kebudayaan harus ditempatkan pada kedudukan yang wajar. Dinilai dan diukur dengan norma dan hukum agama.

b) Kebudayaan yang baik dan tidak bertentangan dengan agama dapat diterima, dari manapun datangnya. Sedangkan yang tidak baik harus ditinggal.

c) Dapat menerima budaya baru yang baik dan melestarikan budaya lama yang masih relevan (al-muhafazhatu 'alal qadimis shalih wal akhdu bil jadidil ashlah).

7) Dakwah

a) Berdakwah bukan untuk menghukum atau memberikan vonis bersalah, tetapi mengajak masyarakat menuju jalan yang diridhai Allah SWT.

b) Berdakwah dilakukan dengan tujuan dan sasaran yang jelas.

c) Berdakwah dilakukan dengan petunjuk yang baik dan keterangan yang jelas, disesuaikan dengan kondisi dan keadaan sasaran dakwah.

3. Aqidah Ahlus Sunnah Wal Jama’ah

a. Dzat dan sifat Allah

Dzat Tuhan tidak dapat dan tidak boleh disamakan dengan (esensi) makhluk. Apabila dalam Al-qur'an disebutkan kata wajah (muka), yad (tangan), dan 'ain (mata) yang dinisbatkan dengan Tuhan aka harus dita'wil seperti ayat di bawah ini 


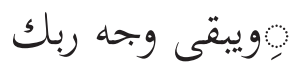

Artinya: Dan tataplah kekal wajah Tuhanmu

Lafad “wajhu” dita’wil menjadi “ dzat Allah “

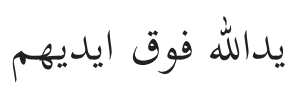

Artinya : tangan Tuhan di atas tangan manusia

Lafad” yatullah " di ta’wil menjadi " kekuasaan Allah “

Sifat-sifat Allah adalah sifat sempurna yang yang tidak terhingga bagi Allah. Sifat-sifat Allah wajib bagi setiap muslim mempercayai bahwa terdapat beberapa sifat kesempurnaan yang tidak terhingga bagi Allah. Maka, wajib juga dipercayai akan sifat Allah yang dua puluh dan Arperlu diketahui juga sifat yang mustahil bagi Allah. Sifat yang mustahil bagi Allah merupakan lawan kepada sifat wajib. Sifat wajib terbagi empat bagian yaitu nafsiah, salbiah, ma'ani atau ma’nawiah.

b. Sifat-sifat wajib Allah

Sifat wajib Allah adalah sifat yang pasti ada pada Allah. Berikut dibawah ini adalah sifat-sifat allah yang wajib :

1) Wujud (ada)

Adanya Allah itu bukan karena ada yang mengadakan atau menciptakan, tetapi Allah itu ada dengan zat-Nya sendiri.

a) Dalil aqli sifat wujud

Adanya semesta alam yang kita lihat sudah cukup dijadikan sebagai alasan adanya Allah, sebab tidak masuk akal seandainya ada sesuatu yang dibuat tanpa ada yang membuatnya.

b) Dalil naqli sifat wujud

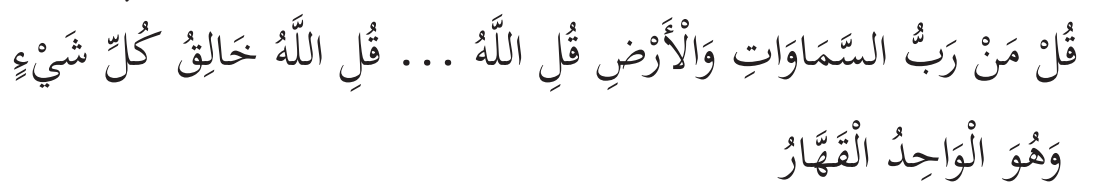

Artinya : Katakanlah: "Siapakah Tuhan langit dan bumi?" Jawabnya: "Allah"....." Katakanlah: "Allah adalah Pencipta segala sesuatu dan Dia-lah Tuhan yang Maha Esa lagi Maha Perkasa". (QS. Ar Ra'du: 16)

2) Qidam (dahulu/awal)

Sifat Allah ini menandakan bahwa Allah swt sebagai pencipta lebih dulu ada 
daripada semesta alam dan isinya yang ia ciptakan.

a) Dalil aqli sifat qidam

Seandainya Allah tidak qodim, mesti Allah hadits, sebab tidak ada penengah antara qodim dan hadits. Apabila Allah hadits maka mesti membutuhkan muhdits (yang membuat) mislanya A, dan muhdits A mesti membutuhkan kepada Muhdits yang lain, misalnya B. Kemudian muhdits B mesti membutuhkan muhdits yang lain juga, misalnya C. Begitulah seterusnya.Apabila tiada ujungnya, maka dikatakan tasalsul (peristiwa berantai), dan apabila yang ujung membutuhkan kepada Allah maka dikatan daur (peristiwa berputar). Masing-masing dari tasalsul dan daur adalah mustahil menurut akal. Maka setiap yang mengakibatkan tasalsul dan daur, yaitu hudutsnya Allah adalah mustahil, maka Allah wajib bersifat Qidam.

b) Dalil naqli sifat qidam

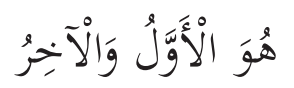

Artinya : Dialah yang awal dan yang akhir. (QS. Al Hadid: 3)

3) Baqa' (kekal)

Allah akan kekal dan abadi selamanya, kekalnya Allah SWT tidak berkesudahan.

a) Dalil aqli sifat baqa'

Seandainya Allah tidak wajib Baqo, yakni Wenang Allah Tiada, maka tidak akan disifati Qidam. Sedangkan Qidam tidak bisa dihilangkan dari Allah berdasarkan dalil yang telah lewat dalam sifat Qidam.

b) Dalil naqli sifat baqa'

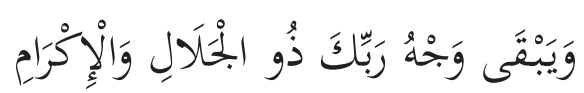

Artinya : Dan tetap kekal Dzat Tuhanmu yang mempunyai kebesaran dan kemuliaan. (QS. Ar Rahman: 27)

4) Mukhalafatuhu Lilhawadith (berbeda dengan ciptaannya/ makhluk-Nya)

Sifat ini menunjukkan bahwa Allah SWT berbeda dengan hasil ciptaan-Nya. Coba kita perhatikan tukang jahit hasil baju yang dijahit sendiri tidak mungkin sama dengan baju yang dibuat orang lain.

a) Dalil aqli sifat mukhalafah lil hawadits

Apabila diperkirakan Allah menyamai sekalian makhluknya, niscaya Allah dalah baru (Hadits), sedangkan Allah baru adalah mustahil 
b) Dalil naqli sifat mukhalafah lil hawadits

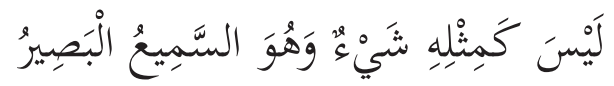

Artinya : Tidak ada sesuatu apapun yang serupa dengan dia, dan dia-lah yang maha mendengar lagi maha melihat. (QS. Asyura: 11)

5) Qiyamuhu Binafsihi (Allah berdiri sendiri)

Artinya bahwa Allah SWT itu berdiri dengan zat sendiri tanpa membutuhkan bantuan yang lain. Maksudnya, keberadaan Allah SWT itu ada dengan sendirinya tidak ada yang mengadakan atau menciptakan. Contohnya, Allah SWT menciptakan alam semesta ini karena kehendak sendiri tanpa minta pertolongan siapapun.

a) Dalil aqli sifat qiyamuhu binafsihi

Seadainya Allah membutuhkan dzat, niscaya Allah adalah sifat, sebab hanya sifatlah yang selalu membutuhkan dzat, sedangkan dzat selamanya tidak membutuhkan dzat lain untuk berdirinya. Dan apabila Allah "Sifat" adalah mustahil, sebab apabila Allah "sifat", maka Allah tidak akan disifati dengan sifat Ma’ani dan Ma'nawiyah, sedangkan sifat tersebut adalah termasuk sifat-sifat yang wajib bagi Allah berdasarkan dalil-dalil tertentu. Berarti apabila Allah tidak disifati dengan sifat Ma'ani dan Ma’nawiyah adalah salah (Bathil), dan batal pula sesuatu yang mengakibatkannya, yaitu butuhnya Allah kepada dzat. Apabila batal butuhnya Allah kepada dzat maka tetap maha kaya (istighna)nya Allah dari dzat. Seandainya Allah membutuhkan sang pencipta, niscaya Allah baru (Hadats), sebab yang membutuhkan pencipta hanyalah yang baru sedangkan dzat qodim tidak membutuhkannya. Dan mustahil Allah Hadits, karena segala sesuatu yang hadits harus membutuhkan sang pencipta (mujid) yang kelanjutannya akan mengakibatkan daur atau tasalul.

b) Dalil naqli sifat qiamuhu binafsihi

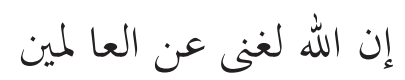

Artinya : Sesungguhnya Allah benar-benar maha kaya (tidak memerlukan sesuatu) dari alam semesta. (QS. Al Ankabut:6)

6) Wahdaniyyah (tunggal/Esa)

Artinya adalah bahwa Allah SWT adalah Tuhan Yang Maha Esa., baik itu Esa zat-Nya, sifat-Nya, maupun perbuatannya. Esa zat-Nya maksudnya zat Allah SWT itu bukanlah hasil dari penjumlahan dan perkiraan atau penyatuan satu unsur dengan unsur yang lain menjadi satu. Berbeda dengan makhluk, makhluk 
diciptakan dari berbagai unsur, seperti wujudnya manusia, ada tulang, daging, kulit dan seterusnya. Esa sifat-Nya artinya semua sifat-sifat kesempurnaan bagi Allah SWT tidak sama dengan sifat-sifat pada makhluk-Nya, seperti marah, malas, dan sombong. Esa perbuatan-Nya berarti Allah SWT berbuat sesuatu tidak dicampuri oleh perbuatan makhluk apapun dan tanpa membutuhkan proses atau tenggang waktu. Allah SWT berbuat karena kehendak-Nya sendiri tanpa ada yang menyuruh dan melarang.

a) Dalil aqli sifat wahdaniyyah

Seandainya Allah ta'addud (tidak tunggal) maka tidak akan ada ciptaan-Nya, karena apabila Allah ada dua tentu mereka akan berbagi pendapat, dan itu mustahil. Maka tidak mungkin Allah ta’addud.

b) Dalil naqli sifat wahdaniyyah

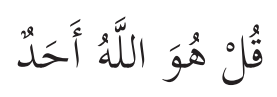

Artinya : Katakanlah: "Dia-lah Allah, yang Maha Esa. (QS. Al Ikhlas: 1)

7) Qudrat (berkuasa)

Kekuasaan Allah SWT, atas segala sesuatu itu mutlak, tidak ada batasnya dan tidak ada yang membatasi, baik terhadap zat-Nya sendiri maupun terhadap makhluk-Nya. Berbeda dengan kekuasaan manusia ada batasnya dan ada yang membatasi.

a) Dalil aqli sifat qudrot

Dalilnya adalah adanya alam semesta. Proses penyusunan dalilnya, jika Allah tidak berkemampuan niscaya Allah lemah ('Ajzun), dan apabila Allah lemah maka tidak akan mampu menciptakan makhluk barang sedikitpun.

b) Dalil naqli sifat qudrot

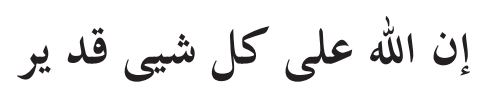

Artinya : Sesungguhnya Allah berkuasa atas segala sesuatu. (QS. AlBaqarah:20)

8) Iradah (berkehendak)

Allah SWT menciptakan alam beserta isinya atas kehendak-Nya sendiri, tanpa ada paksaan dari pihak lain atau campur tangan dari siapapun. Apapun yang Allah SWT kehendaki pasti terjadi, begitu juga setiap sesuatu yang Allah SWT tidak menghendaki pasti tidak akan terjadi. Manusia mempunyai keinginan, tetapi keinginan itu kandas di tengah jalan. Apabila manusia berkeinginan tanpa 
disertai dengan kehendak Allah SWT. Pasti keinginan itu tidak terwujud. Hal ini menunjukkan bahwa manusia memiliki keterbatasan, sedangkan Allah SWT memiliki kehendak yang tidak terbatas. Jadi berbeda dengan kehendak atau kemauan manusia.

a) Dalil aqli sifat irodat

Dalilnya adalah adanya alam semesta. Proses penyusunan dalil, seandainya allah tidak bersifat berkehendak, niscaya bersifat terpaksa (karohah), dan Allah bersifat terpaksa adalah mustahil karena tidak akan disifati qudrot. Akan tetapi tidak disifatinya Allah dengan sifat qudrot adalah mustahil, sebab akan berakibat lemahnya Allah, sedangkan lemahnya Allah adalah mustahil, karena tidak akan mampu membuat makhluk barang sedikitpun.

b) Dalil naqli sifat irodat

$$
\text { ان ربك فعال لمايريد }
$$

Artinya : Sesungguhnya Tuhanmu Maha Pelaksana terhadap apa yang dia kehendaki. (QS. Hud:107)

9) Ilmu (mengetahui)

Artinya Allah SWT memiliki pengetahuan atau kepandaian yang sangat sempurna, artinya ilmu Allah SWT itu tidak terbatas dan tidak pula dibatasi. Allah SWT mengetahui segala sesuatu yang ada di alam semesta, baik yang tampak maupun yang gaib. Bahkan, apa yang dirahasiakan di dalam hati manusia sekalipun. Bukti kesempurnaan ilmu Allah SWT, ibarat air laut menjadi tinta untuk menulis kalimat-kalimat Allah SWT, tidak akan habis kalimat-kalimat tersebut meskipun mendatangkan tambahan air yang banyak seperti semula. Kita sering kagum atas kecerdasan dan ilmu yang dimiliki orang-orang pintar di dunia ini. Kita juga takjub akan indahnya karya dan canggihnya tekhnologi yang diciptakan manusia. Sadarkah kita bahwa ilmu tersebut hanyalah sebagian kecil saja yang diberikan Allah SWT kepada kita.

a) Dalil aqli sifat ilmu

Dalilnya adalah adanya alam semesta. Proses penyusunan dalil, seandainya Allah tak berilmu niscaya tidak akan berkehendak, sedangkan allah tidak berkehendak adalah mustahil, karena tidak akan disifati qudrot, akan tetapi Allah tidak disifati dengan qudrot adalah mustahil, sebab akan berakibat lemahnya Allah. Sedangkan lemahnya Allah adalah mustahil, karena tidak akan mampu membuat barang makhluk sedikitpun. 
b) Dalil Naqli sifat Ilmu

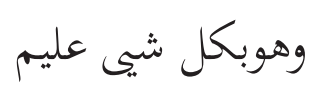

Artinya : Dan dia maha mengetahui segala sesuatu. (QS. Al Hadid:3)

10) Hayat (hidup)

Artinya hidupnya Allah tidak ada yang menghidupkannya. Melainkan hidup dengan zat-Nya sendiri, karena Allah Maha Sempurna. Berbeda dengan makhluk yang diciptakan-Nya. Contohnya: Manusia ada yang menghidupkan. Selain itu, mereka juga membutuhkan makanan, minuman, istirahat, tidur, dan sebagainya. Akan tetapi, hidupnya Allah SWT tidak membutuhkan semua itu. Allah SWT hidup selama-lamanya, tidak mengalami kematian bahkan mengantuk pun tidak.

a) Dalil aqli sifat hayat

Dalilnya adanya alam semesta. Proses penyusunan dalil, seandainya Allah tidak hidup maka tidak akan disifati Qudrot, akan tetapi Allah tidak disifati dengan Qudrot adalah mustahil, sebab akan berakibat lemahnya Allah, sedangkan lemahnya Allah adalah mustahil, karena tidak akan mampu membuat alam semesta.

b) Dalil naqli sifat hayat

$$
\text { وتو كل على الحى الذى لايمو ت }
$$

Artinya : Dan bertakwalah kepada Allah yang hidup yang tidak mati. (QS. Al-Furqon:58)

11) Sama' (mendengar)

Allah SWT mendengar setiap suara yang ada di alam semesta ini. Tidak ada suara yang terlepas dari pendengaran Allah SWT walaupun suara itu lemah dan pelan. Seperti suara bisikan hati dan jiwa manusia. Pendengaran Allah SWT berbeda dengan pendengaran makhluk-Nya, karena tidak terhalang oleh suatu apapun, sedangkan pendengaran makhluk-Nya dibatasi ruang dan waktu. Sesuai dengan ayat Al Qur'an, yaitu :

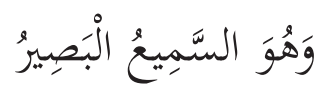

Artinya : Dan Allah-lah Yang Maha Mendengar lagi Maha Mengetahui (QS Al Maidah :76) 
12) Bashar (melihat)

Allah SWT melihat segala sesuatu yang ada di alam semesta ini. Penglihatan Allah bersifat mutlak, artinya tidak dibatasi oleh jarak (jauh atau dekat) dan tidak dapat dihalangi oleh dinding (tipis atau tebal). Segala sesuatu yang ada di alam semesta ini, kecil maupun besar, tampak atau tidak tampak, pasti semuanya terlihat oleh Allah SWT. Sesuai dengan ayat Al Qur'an yaitu :

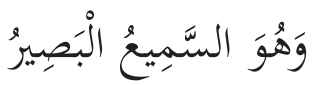

Artinya : Dan Allah-lah Yang Maha Mendengar lagi Maha Mengetahui (QS Al Maidah :76)

Dengan memahami sifat bashar Allah SWT hendaknya kita selalu berhatihati dalam berbuat. Mungkin kita bisa berbohong kepada manusia, seperti orang tua, guru, atau teman. Akan tetapi kita tidak akan bisa berbohong kepada Allah SWT.

13) Kalam (berbicara/berfirman)

Allah SWT bersifat kalam artinya Allah SWT berfirman dalam kitab-Nya yang diturunkan kepada para nabi dan rasul-Nya. Pembicaraan Allah SWT tentu tidak sama dengan pembicaraan manusia karena Allah SWT tidak berorgan (panca indra), seperti lidah dan mulut yang dimiliki oleh manusia. Allah SWT berbicara tanpa menggunakan alat bantu yang berbentuk apapun, sebab sifat kalam Allah SWT sangat sempurna. Sebagai bukti bahwa adanya wahyu Allah SWT berupa Al Qur’an yang diturunkan kepada Nabi Muhammad SAW dan kitab-kitab Allah yang diturunkan kepada para rasul sebelum Nabi Muhammad SAW. Sesuai dengan ayat Al Qur'an yaitu :

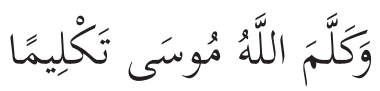

Artinya : "Dan Allah berkata kepada Musa dengan satu perkataan yang jelas” (QS An-Nisa' :164)

Oleh karena itu kita sebagai hamba Allah SWT hendaknya membiasakan diri mengucapkan kalimat-kalimat tayyibah, artinya kata-kata yang mulia, seperti ketika kita berbuat salah, maka segeralah membaca istighfar.

14) Kaunuhu qadiron

Yaitu keadaan Allah Ta’ala yang berkuasa mengadakan dan meniadakan. Sesuai dengan ayat Al Qur'an yaitu : 


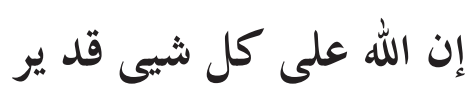

Artinya : Sesungguhnya Allah berkuasa atas segala sesuatu. (QS. Al-Baqarah :20)

15) Kaunuhu muridan

Yaitu keadaan Allah Ta’ala yang menghendaki dan menentukan tiap-tiap sesuatu, Ia berkehendak atas nasib dan takdir manusia. Sesuai dengan ayat Al Qur'an yaitu :

$$
\text { ان ربك فعال لمايريد }
$$

Artinya : Sesungguhnya Tuhanmu Maha Pelaksana terhadap apa yang dia kehendaki. (QS. Hud:107)

16) Kaunuhu 'aliman

Yaitu keadaan Allah Tảala yang mengetahui akan tiap-tiap sesuatu, mengetahui segala hal yang telah terjadi maupun yang belum terjadi, Allah pun dapat mengetahui isi hati dan pikiran manusia. Sesuai dengan ayat Al Quran yaitu :

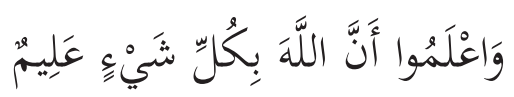

Artinya : Dan ketahuilah bahwasanya Allah Maha mengetahui segala sesuatu. (QS. Al Baqoroh : 231)

17) Kaunuhu hayyan

Yaitu keadaan Allah Ta’ala yang hidup, Allah adalah Dzat yang hidup, Allah tidak akan pernah mati, tidak akan pernah tidur ataupun lengah. Sesuai dengan ayat Al Qur'an yaitu :

$$
\text { وتو كل على الحى الذ ى لايمو ت }
$$

Artinya : Dan bertakwalah kepada Allah yang hidup yang tidak mati. (QS.

Al-Furqon:58)

18) Kaunuhu samian

Yaitu keadaan Allah Ta’ala yang mendengar, Allah selalu mendengar pembicaraan manusia, permintaan atau doa hamba-Nya. Sesuai dengan ayat Al Qur'an, yaitu :

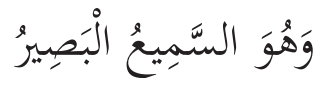


Artinya : Dan Allah-lah Yang Maha Mendengar lagi Maha Mengetahui (QS Al Maidah :76)

19) Kaunuhu basiron

Yaitu keadaan Allah Ta'ala yang melihat akan tiap-tiap yang maujudat (benda yang ada). Allah selalu melihat gerak-gerik kita. Oleh karena itu, hendaknya kita selalu berbuat baik. Sesuai dengan ayat Al Qur'an, yaitu :

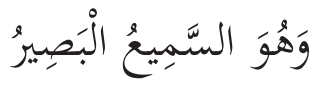

Artinya : Dan Allah-lah Yang Maha Mendengar lagi Maha Mengetahui (QS Al Maidah :76)

20) Kaunuhu mutakalliman

Yaitu keadaan Allah Ta’ala yang berkata-kata, Allah tidak bisu, Ia berbicara atau berfirman melalui ayat-ayat Al Quran. Bila Al Quran menjadi pedoman hidup kita, maka kita telah patuh dan tunduk terhadap Allah SWT.

c. Sifat-sifat mustahil Allah

Sifat mustahil bagi Allah artinya sifat yang tidak mungkin ada pada Allah SWT. Sifat mustahil Allah merupakan lawan kata/kebalikan dari sifat wajib Allah. Berikut di bawah ini adalah 20 sifat-sifat mustahil bagi Allah SWT.

1) Adam, artinya tiada (bisa mati)

2) Huduts, artinya baharu (bisa di perbaharui)

3) Fana', artinya binasa (tidak kekal/mati)

4) Mumathalatuhu Lilhawadith, artinya menyerupai akan makhluk-Nya

5) Qiyamuhu Bighayrih, artinya berdiri dengan yang lain (ada kerjasama)

6) Ta’addud, artinya berbilang-bilang (lebih dari satu)

7) Ajz, artinya lemah (tidak kuat)

8) Karahah, artinya terpaksa (bisa di paksa)

9) Jahl, artinya jahil (bodoh)

10) Maut, artinya mati (bisa mati)

11) Syamam, artinya tuli

12) Umy, artinya buta

13) Bukm, artinya bisu

14) Kaunuhu 'ajizan, artinya lemah (dalam keadaannya)

15) Kaunuhu karihan, artinya terpaksa (dalam keadaannya)

16) Kaunuhu jahilan, artinya jahil (dalam keadaannya) 
17) Kaunuhu mayyitan, artinya mati (dalam keadaannya)

18) Kaunuhu asam, artinya tuli (dalam keadaannya)

19) Kaunuhu a’ma, artinya buta (dalam keadaannya)

20) Kaunuhu abkam, artinya bisu (dalam keadaannya)

d. Sifat ja'iz Allah

Sifat Jaiz bagi Allah artinya boleh bagi Allah SWT mengadakan sesuatu atau tidak mengadakan sesuatu atau disebut juga sebagai "mumkin". Mumkin ialah sesuatu yang boleh ada dan tiada. Ja'iz artinya boleh-boleh saja, dengan makna Allah SWT menciptakan segala sesuatu, yakni dengan tidak ada paksaan dari sesuatupun juga, sebab Allah SWT bersifat qudrat (kuasa) dan iradat (kehendak), juga boleh-boleh saja bagi Allah SWT meniadakan akan segala sesuatu apapun yang ia mau.

\section{Pembahasan}

Dusun Jalen Desa Setail Kec. Genteng mempunyai penduduk yang mayoritas NU atau Ahlus Sunnah Wal Jama'ah memiliki beberapa kegiatan rutinan dan terdapat beberapa organisasi yang sifatnya berbaur dengan masyarakat. Di tengah-tengah organisasi dan kegiatan rutinan tersebut dari pihak ASWAJA NU CENTER ikut membantu baik dalam segi, materi, fikiran bahkan tenaga.

ASWAJA NU CENTER mampu memberikan pelayanan yang terbaik kepada masyarakat dalam membantu tentang pemahaman aqidah yang benar sesuai ajaran Rasulullah SAW yang disebut Ahlus Sunnah Wal Jama'ah. Selain itu, ASWAJA NU CENTER juga sering memberikan motivasi dalam membangun pendidikan yang lebih berkualitas dan berakhlaq. Masyarakatpun sangat antusias dan berterima kasih banyak dengan apa yang sudah diberikan oleh

Dari beberapa hasil laporan dari informan, ASWAJA NU CENTER mempunyai beberapa langkah di antaranya sebagai berikut: mewujudkan wawasan aqidah keislaman ASWAJA sesuai keberagamaan Rasulullah SAW bersama para sahabat. Mengaktualisasi pemahaman umat tentang aqidah keislaman ASWAJA NU, meningkatkan pemahaman, penghayatan, pengalaman (menginternalisasi) aqidah Islam ASWAJA NU sebagai perilaku umat dalam kehidupan sehari-hari, dan menyinergikan antara ajaran agama Islam dengan negara.

Kita bisa menyimpulkan peranan penting ASWAJA NU CENTER dalam membentengi aqidah manusia di berbagai sisi dan dimensi kehidupan dalam poin-poin berikut :

1. Program Uswah (Usaha Sosialisasi Ahlussunnah Waljamaah)

Mensosialisasikan faham ASWAJA ke berbagai elemin masyarakat dengan berbagai cara 
dan $\lambda$ usaha, baik itu melalui lailatul ijtima', pengajian umum, khutbah jumat, penerbitan, media cetak dan elektronik, program Uswah ini juga ditrapkan di Desa jalen melalui kegiatan yang sama yakni materi khutbah dibuat oleh pengurus ranting bekerja sama dengan MWC NU kecamatan Genteng yang isinya di sesuikan dengan situasi yang ada dan lebih ditekankan pada penguatan aqidah ahlus sunnah waljama’ah dan yang menarik lagi setiap juma'at pengurus MWC NU membuat buletein NU yang disebar di masjid se Desa Setail

\section{Biswah (Bimbingan Dan Solusi Ahlussunnah Waljamaah)}

Menjadwal pengurus syuriyah NU secara berkala untuk membimbing dan memberikan solusi $\lambda$ kepada masyarakat yang mau bertanya tentan faham ASWAJA, baik langsung atau, telphon atau media lain. Program Biswah ini juga dilakukan oleh oleh pengurus NU Setail, yang sasarannya adalah pengurus Banom NU yakni Fatayat, muslimat, IPNU dan IPPNU dengan cara membuat buku rangkuman hasil bahsul masil yang perna diusulkan oleh masyarakat Desa Setail, kemudian dibagikan kepada anggota

\section{Dakwah (Daurah Kader Ahlussunnah Waljamaah)}

Mengadakan pelatihan kader ASWAJA secara berkala untuk mencetak kader militan pembela $\lambda$ faham ASWAJA dengan materi pokok: a. qonun asasi NU b. fikrah Nahdliyah c. Pendalam pengertian ASWAJA NU d. Memahami dalil dan hujah amaliyah NU seperti tahlil, istighotsah, tawassul dll. e. Memahami firqah2 diluar NU

\section{Kiswah (Kajian Islam Ahlussunnah Waljamaah)}

Mengadakan kajian islam aswaja ditinjau dari berbagia disiplin ilmu dalam bentuk halaqah, $\lambda$ seminar atau forum ilmiyah lain dengan menghadirkan nara sumber dari berbagai ahli. Diadakan secara berkala dan terprogram.

Program Aswaja NU Center tersebut sudah di respon oleh masyarakat, lebih lebih pengurus NU Desa Jalen, hal ini berdasarkan hasil wawancara dengan tokoh-tokoh NU Desa Jalen yang intinya dalam rangka membentengi ajaran Aswaja NU dengan berbagai cara yaitu:

1. Membentengi aqidah masyarakat Setail melaui organisasi yang ada di masyarakat seperti Remas, IPNU, IPPNU, Muslimat, Fatayat, dan lain-lain. Dari beberapa organisasi tersebut bisa memperkokoh aqidah Ahlus Sunnah Wal Jama’ah sehinnga bisa menjaga Agama Islam dengan basis Ahlus Sunnah Wal jama'ah.

2. Mengoptimalisasikan kegiatan keislaman yang berbau Ahlus Sunnah Wal Jama’ah yang tujuannya untuk membentengi aqidah masyarakat yang ada di di Desa Setail

3. Mengadakan pelatihan atau workshop tentang aqidah Ahlus Sunnah Waljamảah yang diikuti oleh Pengurus Ranting, Banom NU termasuk imam masjid dan mushola

4. Mengadakan peringatan Hari Besar Islam seperti Mauludan, Isro’ Mi'roj, Tahun Baru Islam yang ceramahnya di isi oleh Kiyai atau pengurus ASWAJA NU CENTER yang memberikan ceramah agama demi meningkatkan ketahanan aqidah Aswaja 
5. Memberikan pelatihan seputar ASWAJA di setiap jam'iyyah, mushola dan masjid di bidang Ubudiyah, Muamalah/perekonomian dll.agar masyarakat $\mathrm{Nu}$ hususnya Desa Jalen tidak ketinggalan informasi

\section{Kesimpulan}

Pertama, Program Uswah (Usaha Sosialisasi Ahlussunnah Waljamaah), melalui sosialisasikan faham ASWAJA ke berbagai elemin masyarakat dengan berbagai cara dan $\lambda$ usaha, baik itu melalui lailatul ijtima', pengajian umum, khutbah jumat, penerbitan, media cetak dan elektronik

Kedua, Biswah (Bimbingan Dan Solusi Ahlussunnah Waljamaah) Menjadwal pengurus syuriyah NU secara berkala untuk membimbing dan memberikan solusi $\lambda$ kepada masyarakat yang mau bertanya tentan faham ASWAJA, baik langsung atau, telphon atau media lain.

Ketiga, Dakwah (Daurah Kader Ahlussunnah Waljamaah) Mengadakan pelatihan kader ASWAJA secara berkala untuk mencetak kader militan pembela $\lambda$ faham ASWAJA dengan materi pokok: a. qonun asasi NU b. fikrah Nahdliyah c. Pendalam pengertian ASWAJA NU d. Memahami dalil dan hujah amaliyah NU seperti tahlil, istighotsah, tawassul dll. e. Memahami firqah2 diluar NU

Kempat, Kiswah (Kajian Islam Ahlussunnah Waljamaah) Mengadakan kajian islam aswaja ditinjau dari berbagia disiplin ilmu dalam bentuk halaqah, $\lambda$ seminar atau forum ilmiyah lain dengan menghadirkan nara sumber dari berbagai ahli. Diadakan secara berkala dan terprogram.

\section{Referensi}

Arikunto, Suharsimi, 2006. Prosedur Penelitian Suatu Pendekatan Praktik, Jakarta: Rineka Cipta

Asy'ari, Hasyim, 1415 H. Risalah Ahl al-sunnah wal Jama'ah fi Hadithal-Mawta wa Ashrat al-Sa ah wa Bayan Mafhum al-Sunna wa al-Bid ah. Jombang: Maktabah al-Turath al-Islami.

Baehaqi, Imam, 2000. Kontroversi Aswaja, Aula Perdebatan dan Interpretasi. Yogyakarta: LkiS.

Chalim, Asep Saifuddin, 2012. Membumikan Aswaja Pegangan Guru NU. Surabaya: Khalista.

Fadeli, Soeleiman dkk. 2012. Antologi NU Buku I, Sejarah-Istilah-Amaliah-Uswah. Surabaya: Khalista

Fadeli, Soeleiman dkk. 2014. Antologi NU Buku II, Sejarah-Istilah-Amaliah-Uswah. Surabaya: Khalista

Hadi, Sutrisno. 2008. Metode penelitian suatu pendekatan proposal, Jakarta: Gramedia 
Jum'ah, Ali. 2012. Bukan Bid'ah, Menimbang Jalan Pikiran Orang-Orang yang Bersikap Keras dalam Beragama. Tangerang Selatan: Lentera Hati

Mastuki, Kiai. 1999. Menggugat, Mengadili Pemikiran Kang Said. Jakarta: Fatma Press

Mustamar, Marzuqi. 2007. Terjemah Kitab Al Muqtatofat Li Ahlil Bidayat. Terjemahan oleh Tim Aswaja Center Darussalam. 2013. Banyuwangi: Yayasan Pondok Pesantren Darussalam Blokagung Tegalsari Banyuwangi

Rifai, Muhammad. 2009. KH. M. Hasyi Asy’ari Biografi Singkat 1871-1947. Jogjakarta: Garasi Siradj, Said Agil. 1997. Ahlussunnah Waljamaah dalam Lintasan Sejarah. Yogyakarta: LKPSM Siradj, Said Agil. 2006. Tasawuf Sebagai Kritik Sosial, Mengedepankan Islam Sebagai Inspiras Bukan Aspirasi, Bandung: Mizan

Tim Aswaja NU Center PWNU Banyuwangi. 2015. Risalah Ahlussunnah Wal-Jamaiah. Surabaya: Khalista

Zuhri, Achmad Muhibbin. 2010. Pemikiran KH. M. Hasyim Asy’ari tentang Ahl Al-Sunnah Wa Al-Jama'ah. Surabaya: Khalista 